\title{
Canadian Urological Association guideline on androgen deprivation therapy: Adverse events and management strategies
}

Andrea Kokorovic, MD ${ }^{1}$; Alan I. So, $\mathrm{MD}^{2}$; Hosam Serag, $\mathrm{MD}^{2}$; Christopher French, $\mathrm{MD}^{3}$; Robert J. Hamilton, MD ${ }^{4}$; Jason P. Izard, MD ${ }^{5}$; Jasmir G. Nayak, MD ${ }^{6}$; Fréderic Pouliot, MD 7 ; Fred Saad, MD ${ }^{1}$; Bobby Shayegan, $\mathrm{MD}^{8}$; Armen Aprikian, MD ${ }^{9}$; Ricardo A. Rendon, MD ${ }^{10}$

${ }^{1}$ Centre Hospitalier de l'Université de Montréal, Montreal, QC, Canada; ${ }^{2}$ Department of Urological Sciences, University of British Columbia, Vancouver, BC, Canada; ${ }^{3}$ Department of Surgery, Division of Urology, Memorial University, St. John's, NL, Canada; ${ }^{4}$ Division of Urology, Department of Surgery, Princess Margaret Cancer Centre, Toronto, ON, Canada; ${ }^{5}$ Department of Urology, Queen's University, Kingston, ON, Canada; ${ }^{6}$ Section of Urology, Department of Surgery, University of Manitoba, Winnipeg, MB, Canada; ${ }^{7} \mathrm{CHU}$ de Quebec, Université Laval, Quebec City, QC, Canada; ${ }^{8}$ Department of Surgery (Urology) and Oncology, McMaster University, Hamilton, ON, Canada; ${ }^{9}$ McGill University Health Centre, Montreal, QC, Canada; ${ }^{10}$ Department of Urology, Dalhousie, University, Halifax, NS, Canada

Cite as: Kokorovic A, So AI, Serag H, et al. Canadian Urological Association guideline on androgen deprivation therapy: Adverse events and management strategies. Can Urol Assoc J 2021 April 21; Epub ahead of print. http://dx.doi.org/10.5489/cuaj.7355

Published online April 21, 2021 $* * *$

\section{Introduction}

Prostate cancer (PC) is the most common type of malignancy in Canadian men. It is expected that 23,300 new cases of PC will be diagnosed in 2020, resulting in 4,200 deaths (1).

Advanced PC describes several disease states, including locally advanced or de novo metastatic disease (approximately $25 \%$ of newly diagnosed cases (2)), recurrent disease following primary treatment and castrate resistant prostate cancer (CRPC). Despite significant advancements in the management of advanced PC over the past several years,

\section{TOPICS:}

1. Introduction

2. Methods

3. Complications of ADT

3.1 Cardiometabolic health

3.1.1. Cardiovascular complications

- Cardiac complications

- Venous thromboembolism and cerebrovascular events

3.1.2. Body composition

3.1.3. Metabolic changes

3.1.4 Management of cardiovascular complications, body composition and metabolic changes

- Screening and treatment

- Exercise therapy

\subsection{Bone health}

3.2.1. Effects of ADT on bone health

3.2.2. Assessment of bone health and fracture risk

3.2.3. Management of bone complications

3.3 Hot flashes

3.4 Breast events

3.5 Cognitive function

3.6 Fatigue and anemia

3.7 Sexual function and body image

3.8 Health related quality of life (HRQOL)

3.8.1. Impact of ADT on HRQOL

3.8.2. Exercise therapy for improving $\mathrm{HRQOL}$ 3.8.3. Intermittent ADT

4. Conclusions and future directions 
androgen deprivation therapy (ADT) remains the backbone of treatment. Additionally, ADT is used in localized disease among patients treated with radiation therapy (RT). Hence, ADT plays an important role in the contemporary management of $\mathrm{PC}$ across various stages of the disease.

While ADT remains a highly effective treatment for PC it is not curative, and its use is associated with significant adverse events that have the potential to cause significant morbidity. Recent therapeutic advancements have significantly improved outcomes and prolonged survival in patients with advanced disease. As such, the management and mitigation of ADT-related adverse events becomes a critical aspect of medical care for these men. The purpose of this guideline is to summarize the major adverse events associated with conventional ADT and provide evidence-based strategies to mitigate them. A summary of currently available agents is listed in Table 1.

\section{Methods}

EmBASE and Medline databases were accessed to identify all relevant articles focused on adverse events related to ADT from inception to December 2020. The following key-word search strategy was used: "prostate cancer," "androgen deprivation therapy," "complications," "adverse events," "side effects,". Reference lists of review articles were searched for any missing articles not captured by our search strategy. Evidence based guidelines on side effects of ADT were retrieved and considered for additional source data. A complete bibliographic review of these guidelines was performed, and studies related to side effects of ADT were reviewed in full. An expert panel comprised of urologists with significant experience prescribing and managing adverse events related to ADT was used to develop the recommendations. Guideline statements have been assigned a level of evidence (LE) using criteria from the Oxford Center for Evidencebased Medicine (3). Each statement is also given a strong, moderate or weak recommendation that was made based on subjective consensus recommendation using best available evidence (3) (4). "Strong" recommendations have been assigned if the statement is supported by high-quality and consistent evidence or in situations where unanimous expert consensus is present. In these cases, additional research has low likelihood of changing the strength of the recommendation. "Weak" recommendations are supported by low quality evidence and there is a large amount of uncertainty regarding the statement. "Expert opinion" statements are not supported by explicit evidence, however, have sufficient biological plausibility to warrant a recommendation.

\section{Complications of ADT}

The castrate levels of testosterone induced by ADT result in adverse effects that span across various organ systems. These untoward side effects have the potential to cause significant morbidity and may alter health related quality of life (HRQOL) in men living with PC. Fortunately, most of these complications are not dose limiting and can be managed through pharmacological or other interventions. Another important consideration is the testosterone flare associated with initiation of luteinizing hormone-releasing hormone (LHRH) agonists, which can be mitigated by the addition of a first generation anti-androgen (AA) for the first 2 to 4 weeks of treatment (5) (6). In partnership with a multidisciplinary team, the overall goal of the urologist is 
to optimize oncological outcomes while maintaining acceptable HRQOL. For this, an in-depth understanding of treatment related adverse events is required to offer appropriate patient counseling and to manage complications. For the purpose of this guideline, we focus only on adverse effects as a result of the use of LHRH agonists and antagonists. The ADT-related complication is listed then followed by a summary of the evidence, a summary of recommendations and subsequently a review of the data used to formulate the guideline statements.

\subsection{Cardiometabolic health}

The term cardiometabolic health collectively refers to the effects of ADT on cardiovascular disease (CVD), body composition and metabolic parameters (including lipid profiles, insulin resistance and glucose homeostasis).

\section{Summary of evidence}

- Cardiac complications:

- ADT may increase the risk of cardiac complications, especially in patients with preexisting CVD or a history of major adverse cardiac events (MACE).

- Thromboembolic and cerebrovascular events:

- ADT may increase the risk of venous thromboembolism (VTE) and stroke.

- Body composition:

- ADT is associated with changes in body composition, including increased body weight and fat mass, decreased lean body mass and decreased muscle mass.

- Metabolic parameters:

- The metabolic complications of ADT include insulin resistance, glucose intolerance and changes in lipid profile.

- ADT is associated with increased risk of incident diabetes and may worsen glycemic control in men with a pre-existing diagnosis.

- Men receiving ADT may be at risk for developing metabolic syndrome.

\section{Recommendations}

- The patient's primary care provider should be informed that the patient has been initiated on ADT, and that there may be adverse events associated with this therapy (Expert opinion).

- Lifestyle modifications (smoking cessation, dietary modifications, exercise) should be strongly encouraged (Expert opinion).

- Providers should obtain a comprehensive baseline physical examination prior to ADT initiation that includes blood pressure, weight, waist circumference and calculation of body mass index (BMI) (Expert opinion).

- Providers should order baseline laboratory investigations including fasting plasma glucose and lipid profile (triglycerides, LDL cholesterol, HDL cholesterol and total cholesterol) (Expert opinion). 
- Patients should be screened for diabetes with fasting plasma glucose, oral glucose tolerance test or Hgb A1c level (Expert opinion).

- Patients should have their blood pressure monitored and hypertension should be treated (Expert opinion).

- Dyslipidemia should be treated according to current best practice guidelines (Expert opinion).

- The above metabolic assessments should be continued at 6-12 month intervals for a minimum of 24 months from treatment initiation (Expert opinion).

- Patients should be encouraged to attend supervised exercise programs using a combination of resistance and aerobic training (LE 2, strong recommendation).

- In patients with a history of myocardial infarction (MI) or stroke, referral to a cardiologist or cardio-oncologist may be considered for assessment and medical optimization prior to initiating ADT (Expert opinion).

- Use of a GnRH antagonist may be considered in men with a prior history of myocardial infarction or stroke ( $L E 2$, weak recommendation).

\subsubsection{Cardiac complications}

The leading cause of death in men with PC not dying of the disease itself is CVD (7). Initial reports describing this potential link emerged more than a decade ago and led to an advisory statement from the American Heart Association, American Cancer Society, and American Urological Association in 2010 (8). Subsequently, the FDA and Health Canada updated the safety warning label on gonadotropin releasing hormone $(\mathrm{GnRH})$ agonist products to include the risk of CVD (9) (10).

Large observational cohort studies describe a strong link between ADT and CVD, including coronary heart disease, MI and sudden cardiac death (11) (12)

(13) (14) (15). However, ad hoc analyses from randomized control trials (RCTs) in the RT literature have failed to consistently demonstrate this association (16) (17) (18) (19). Several meta-analyses have attempted to address these discrepant findings. Zhao et al. performed a metaanalysis of population based observational studies addressing the association of cardiovascular morbidity or mortality with use of ADT in over 119,000 PC patients (20). The authors concluded that use of ADT was associated with a significant risk of cardiovascular mortality (hazard ratio (HR) 1.17 ; $95 \%$ confidence interval (CI): 1.04-1.32; $\mathrm{p}=0.01$ ). Another meta-analysis that included 8 observational studies found a $38 \%$ increase in nonfatal CVD for men treated with a GnRH agonist compared to those without (relative risk (RR) 1.38, 95\% CI: 1.29-1.48) (21). In contrast, Nguyen et al. found no association between use of a GnRH agonist and cardiovascular death in a pooled analysis of eight RCTs that included over 4000 men (22). The authors concluded that use of ADT lowers prostate-cancer specific and all-cause mortality without increasing risk of cardiovascular death.

There appears to be discrepancy between results of population-based observational studies compared to those of RCTs from the RT literature on the association between ADT use 
and CVD. It is plausible that there are confounding factors not accounted for in database studies which may contribute to the higher $\mathrm{CV}$ event rates that were not in general observed in RCTs. On the other hand, the RCTs were not designed with MACE as a primary outcome measure, and therefore would likely be underpowered to detect a difference given the low event rate. It is also important to note that the RCT data does not stratify results based on CVD history in individual patients, and therefore the conclusions need to be interpreted with caution. Overall, the large population-based observational data provides sufficient evidence to suggest a link between use of ADT and CVD.

The presence of pre-existing heart disease appears to be a major risk factor for development of MACE in men receiving ADT. MACE is a cumulative term for adverse CV events and is defined as MI, coronary revascularization, stroke, and hospitalization because of heart failure. In one study, men who experienced two or more MACE before initiation of ADT were at highest risk for developing CVD during the first 6 months of therapy (HR 1.91, 95\% CI: 1.66-2.20 for GnRH agonist versus no treatment) compared to an age-matched cohort from the general population (23). Ziehr et al found no association between ADT and cardiac-specific mortality in men without any cardiac risk factors (defined as congestive heart failure (CHF) or prior MI) (24). However, men with a history of these risk factors treated with ADT had a significantly higher risk of cardiac mortality compared to those without treatment at 5 years (HR 3.28, 95\% CI: $1.01-10.64 ; \mathrm{p}=0.048)$. A similar association was also reported by Nanda et al using similar cardiac risk stratification (25). Importantly, even short durations of ADT (ie. 3 to 6 months) appear to increase CVD risk (19). Together, the data suggests that men with pre-existing cardiac disease are at highest risk for developing MACE.

An important area of debate is whether treatment with a GnRH agonist versus antagonist results in a different risk profile with respect to CVD and development of MACE. Studies in animal models suggest that GnRH agonists, but not antagonists, may induce plaque instability and rupture (26) (27), however whether this translates to clinical practice remains unknown. A pooled analysis of 6 RCTs including 2328 men found that those with pre-existing CVD treated with a GnRH antagonist were $56 \%$ less likely to have a cardiovascular event within 1 year of beginning ADT compared to men treated with a GnRH agonist (HR 0.44; 95\% CI: 0.26-0.74, $\mathrm{p}=0.002$ ) (28). However, this data is limited by results obtained from post hoc analysis, short follow up less than one year and exclusion of patients with certain pre-existing cardiac risk factors. The results of this study are supported by a recent phase II trial in which patients using a GnRH antagonist were 18\% less likely to experience a MACE (95\% CI: 4.6-31.2) (29). However, a large population based study from France did not identify a difference between the two treatment modalities (30).

Recently, the efficacy and safety of the oral GnRH antagonist relugolix compared with leuprolide was investigated in the pivotal phase III HERO clinical trial (31). Men with advanced PC were randomized to receive relugolix or leuprolide for 48 weeks. The primary outcome was sustained castrate levels of testosterone $(<50 \mathrm{ng} / \mathrm{dl})$ throughout trial duration. Relugolix was noninferior and superior to leuprolide in achieving castrate testosterone levels through 48 weeks, 
as well as at days 4 and 15. Development of MACEs were studied as part of pre-specified safety analysis. MACE was defined as nonfatal MI, nonfatal stroke, and death from any cause. Men treated with relugolix had a 2.9\% incidence of MACE (exact 95\% CI, 1.7-4.5) compared with $6.2 \%$ in the leuprolide arm (exact 95\% CI, 3.8 - 9.5) at 48 weeks, which represented a 54\% decrease in risk (HR 0.46; 95\% CI: 0.24-0.88). In men with a prior medical history of MACE (as defined in the trial), the incidence of new MACE appeared to be more pronounced (3.6 vs 17.8\% in the relugolix and leuprolide arms, respectively). Overall, the data suggest that men with prior history of MACE receiving leuprolide are 4.8 times more likely to experience MACE than those on relugolix.

Several trials are underway to address cardiac outcomes in men receiving ADT. The cardiovascular safety of degarelix versus leuprolide in men with advanced PC and pre-existing CVD is being investigated by the PRONOUNCE trial, where the primary outcome measure is time to first MACE endpoint (PRONOUNCE ClinicalTrials.gov identifier: NCT02663908). Additional insight will come from the RAndomizeD Intervention for Cardiovascular and Lifestyle Risk Factors in Prostate Cancer Patients (RADICAL-PC) trial. This trial is designed to assess the impact of systematic lifestyle and cardiovascular risk factor modification in men with prostate cancer, with a focus on ADT (ClinicalTrials.gov Identifier: NCT03127631). The primary outcome measure is a composite occurrence of cardiovascular death, MI, stroke, heart failure, or arterial revascularization.

\section{Venous thromboembolism and cerebrovascular events}

The outcome definitions for cardiovascular complications vary across studies, and some have included stroke and/or VTE. The pathophysiology behind ADT and cerebrovascular events is not fully understood, but one explanation is that GnRH agonists may destabilize atherosclerotic plaques (26) (27) (28). The association between estrogen containing compounds and thromboembolic events is well characterized, however the risk incurred with non-estrogen containing ADT requires further study.

Using the Surveillance, Epidemiology, and End Results (SEER) database, an analysis including 59,000 men by Ehdaie et al found that ADT was associated with increased risk of deep vein thrombosis (DVT), pulmonary embolus (PE) or arterial embolism (32). Similarly, Kili-Drori et al found an association between ADT use and VTE-related hospitalization (33). Men receiving ADT were $84 \%$ more likely to be hospitalized with DVT, PE or both. Two recent meta-analyses demonstrated an increased risk of DVT and PE in men with PC receiving ADT in the absence of estrogen (34) (35). Currently, there is insufficient evidence to recommend routine use of VTE prophylaxis in men receiving ADT.

Similar associations have been found for cerebrovascular events. A large observational study of over 37,000 men with local or regional PC receiving GnRH agonist experienced a significantly increased risk of stroke compared to the no treatment group (HR 1.22, 95\% CI:1.10 to 1.36) (13). Longer durations of ADT were associated with an increased number of these events. A meta-analysis of 8 observational studies found a $51 \%$ increase in relative risk of stroke 
for men treated with a GnRH agonist compared to those without (RR 1.51, 95\% CI:1.24-1.84) (21).

\subsubsection{Body composition}

Androgens are well known moderators of body habitus in men. Patients treated with ADT experience an increase in body weight and percentage fat mass, which is largely due to an accumulation of subcutaneous fat, rather than intraabdominal adipose tissue (36) (37) (38). A meta-analysis examining the effect of ADT on body composition that included 16 longitudinal studies found an increase in percentage body fat by 7.7\% (95\%CI: 4.3-11.2, p<0.0001) (39). The authors also found a significant increase in body weight and BMI. These changes are thought to occur soon after initiating therapy, sometimes as early as one month following treatment (39). Longer duration of therapy appears to increase weight gain and percentage fat mass (39), and these changes may persist up to two years beyond treatment cessation (40). ADT also causes a loss of muscle mass with a resultant decrease in percentage lean mass (36) (31) (41). In their meta-analysis on the effect of ADT on body composition, Haseen et al demonstrated an overall decrease in percentage lean body mass by $2.8 \%$ (95\% CI: -3.6 to $-2.0, \mathrm{p}<0.0001)$ (39).

The loss of lean body mass and accumulation of fat mass is collectively termed sarcopenic obesity and has important implications. A decrease in muscle mass causes a decrease in grip strength, absolute muscular strength, and gait speed (42). ADT also results in detrimental changes to multiple other physical parameters, including aerobic fitness and overall physical function (42) (43). Together, these changes may contribute to morbidity in this patient population by increasing falls and fracture risk (44).

Population based studies suggest that an elevated BMI may be associated with PC progression and death (45) (46) (47). There may also be an association between obesity and development of CRPC and metastases in men treated with early ADT (48). The mechanistic links and causal relationship between obesity and PC remain unclear. Nonetheless these findings, in addition to multiple metabolic and cardiovascular complications resulting from obesity, hold important implications for men with PC treated with ADT.

\subsubsection{Metabolic changes}

The metabolic consequences of ADT include insulin resistance, glucose intolerance and changes to lipid profile (49) (50). In a study of over 70000 men, Keating et al demonstrated that men receiving ADT were more likely to develop incident diabetes compared to non-ADT controls (12). Two additional population based studies also demonstrated similar findings, with an increased association of ADT and incident diabetes by 16-28\% (13) (51). In addition, use of ADT may worsen glycemic control in men with pre-existing insulin dependent diabetes (52). ADT also appears to change the lipid profile, although results describing these changes are conflicting (53) (54) (55) (56) (57) (58). Overall, most studies have consistently found an increase in triglyceride and total cholesterol levels, however the cause of this rise (ie. whether due to high density lipoprotein (HDL) or low density lipoprotein (LDL) cholesterol) remains to be determined. 
This constellation of findings overlaps with the metabolic syndrome, which is defined in slightly different ways by different organizations. As an example, the National Cholesterol Education Program (NCEP) Adult Treatment Panel III (ATP III) defines metabolic syndrome as meeting three of the following criteria (59): waist circumference $\geq 102 \mathrm{~cm}$ in men, serum triglycerides $\geq 1.7 \mathrm{mmol} / \mathrm{L}$, serum $\mathrm{HDL}$ cholesterol $<1 \mathrm{mmol} / \mathrm{L}$ in men, blood pressure $\geq 130 / 85$ $\mathrm{mmHg}$, fasting plasma glucose $\geq 5.6 \mathrm{mmol} / \mathrm{L}$ or requirement for medications to treat criteria $2-5$ listed above. In one study, ADT was associated with higher risk of metabolic syndrome compared to controls, with more than $50 \%$ of men on ADT meeting criteria for metabolic syndrome (58). The diagnosis of metabolic syndrome was attributable to an elevation of triglycerides, hyperglycemia and abdominal obesity. This is an important finding, as patients with a diagnosis of metabolic syndrome are more likely to develop type 2 diabetes and CVD. These men require early identification and intervention to mitigate this risk.

Metformin has been investigated as a potential treatment for ADT-induced metabolic changes. In a small study of 40 men, 6 months of metformin combined with exercise resulted in decreased abdominal girth, BMI and blood pressure (60). There is currently insufficient evidence to recommend metformin prophylactically in men receiving ADT. The PRIME trial (ClinicalTrials.gov identifier: NCT03031821) is designed to specifically address this question and may provide further guidance in the future.

\subsubsection{Management of cardiovascular complications, body composition, and metabolic changes}

Current Canadian guidelines for prevention and management of CVD and dyslipidemia do not specifically address men receiving ADT. The Canadian Cardiovascular Harmonized National Guidelines Endeavour (C-CHANGE) for prevention and management of cardiovascular disease is aimed at identifying and managing patients who are at risk for developing CVD, including those with or at risk for diabetes and dyslipidemia (61). Hence, a reasonable approach to the management of men on ADT is to adopt these guidelines for both a screening and management strategy. Accordingly, men should be encouraged to moderate their caloric intake and adapt healthy dietary patterns to decrease their risk of CVD. Smoking cessation should be strongly encouraged and blood pressure should be regulated to a target level of $<130 / 80$. Diabetes screening with a fasting plasma glucose level, hemoglobin A1c or oral glucose tolerance test should be performed at the time of ADT initiation, as well as 6 months and 12 months following initiation of treatment. Baseline lipid profiles (triglycerides, LDL cholesterol, HDL cholesterol and total cholesterol) should be obtained at the start of ADT and monitored throughout treatment duration. Management of dyslipidemia and lipid targets should be carried out according to 2021 Canadian Cardiovascular Society Guidelines for the Management of Dyslipidemia for the Prevention of Cardiovascular Disease in the Adult [62]. For patients at high risk for CVD, referral to cardiology or cardio-oncology should be made for further assessment of risk event profile.

Pharmacological therapy should be considered as per current best practice in high-risk individuals according to the C-CHANGE guidelines. This includes statins, aspirin, angiotensin 
converting enzyme inhibitors for primary and secondary prevention. The effect of these interventions in reducing cardiovascular morbidity in men with PC receiving ADT requires further validation with randomized prospective trials, such as RADICALS-PC as described earlier.

It is evident that exercise has multiple beneficial effects in PC patients receiving ADT. Specifically, muscle loss and the resultant decline in lean body mass may be prevented with resistance training (63) (64) (65). A prospective study found significant improvements in lean mass, appendicular skeletal muscle mass, muscle strength and physical function in men undergoing 3 or 6 months of supervised resistance-based multimodal training (66). Other benefits of exercise include decreases in BMI, fat mass and glucose levels, as well as improvements in lipid profiles and insulin sensitivity (43) (63). In addition to improving metabolic indices and body composition, exercise therapy may ameliorate cardiovascular outcomes. For example, a 3 to 6 month supervised exercise program consisting of resistance and aerobic training in men receiving ADT improves peak oxygen consumption and a 400 meter walk test (67) (68). Other authors have demonstrated an improvement in endothelial function in men on long term ADT in response to supervised exercise and dietary intervention (69).

Together, these data support the use of a supervised exercise regimen using a combination of resistance and aerobic training to improve body composition and metabolic profiles of men receiving ADT, as well as overall physical and mental well-being. The 2018 American College of Sports and Medicine Roundtable recommendations provide detailed evidence-based guidance for exercise training in cancer survivors to improve fatigue, anxiety, depression, function and quality of life (70). Furthermore, the Exercise for People with Cancer Guideline Development Group, organized through Cancer Care Ontario, recommends 150 minutes of moderate intensity aerobic exercise spread over 3-5 days in addition to resistance training 2 to 3 times per week (71). Resistance training should engage 8-10 muscle groups and include 8-10 repetitions with 2 sets. These interventions should be continued on an ongoing basis, and patients should be assessed for appropriateness to engage in rigorous physical activity prior to and during therapy. Studies suggest that supervised exercise therapy in men with PC is superior to self-implemented exercise regimens (43).

Given the complexities of exercise oncology, the ideal management would be referral to a professional (ie. exercise physiologist, certified exercise instructor, community program etc.) who can deliver supervised intervention tailored to men with PC. We encourage physicians prescribing ADT to become familiarized with regional resources that are available to patients. A summary of the benefits of exercise therapy is found in Table 2 .

\subsection{Bone health}

\section{Summary of evidence}

- Use of ADT in men with PC has detrimental effects on bone health, including decreased bone mineral density (BMD), osteoporosis and increased risk for clinical fractures. 


\section{Recommendations}

- A comprehensive history and physical examination to include falls risk and height measurement should be performed prior to initiating ADT (Expert opinion).

- Patients should be counselled regarding smoking and alcohol cessation (Expert opinion).

- Patients should be encouraged to participate in exercise therapy using a combination of resistance and aerobic training, preferably in a supervised setting (LE 2, strong recommendation).

- Providers should obtain baseline calcium and 25-hydroxyvitamin D levels at the start of ADT (Expert opinion).

- Men should maintain adequate calcium intake (1200 mg PO daily from dietary sources and supplements) (Expert opinion).

- Vitamin D supplementation (800-2000 IU PO daily) should be initiated at the start of ADT (Expert opinion).

- Providers should screen men initiating long-term ADT for osteoporosis using BMD testing with dual energy $x$-ray absorptiometry (DXA) (as per the 2010 clinical practice guidelines for the diagnosis and management of osteoporosis in Canada) (Expert opinion).

- A 10-year major osteoporotic fracture risk using a validated tool should be calculated (Expert opinion).

- Men diagnosed with osteoporosis, those with history of fragility fractures in the hip or spine, those with a history of multiple fragility fractures, or those with a moderate or high 10-year fracture risk should be treated with a bisphosphonate or denosumab at doses recommended for the general population ( $L E 1$; strong recommendation).

- DXA should be repeated every 2-3 years in men at low risk for fractures receiving ADT. In men with osteopenia or those at moderate or high risk for fractures, DXA should be repeated every 1-2 years until treatment cessation. Patients started on pharmacological therapy should have follow-up DXA to assess for treatment response (Expert opinion).

\subsubsection{Effects of ADT on bone health}

Men with PC comprise mostly an older population that has an increased risk for osteoporosis, even in the absence of ADT (72) (73). In addition, ADT has been shown to decrease BMD, resulting in osteoporosis and an increased risk for clinical fractures (74) (75) (76) (77). A large prospective cohort study demonstrated that use of ADT resulted in a $2.5 \%$ decrease in BMD at the femoral neck and $4.0 \%$ at the lumbar spine at 12 months of therapy, compared to no significant change in healthy age-matched controls and men with PC not receiving ADT (78). BMD loss occurs at a maximum rate during the first year of therapy, however continues to decline with prolonged use of ADT (74) (79) (80). 
Men receiving ADT are at increased risk for fractures (77) (80) (81). In a large observational study of over 50,000 men, those receiving ADT had a fracture incidence of $19 \%$ within five years of PC diagnosis compared to $13 \%$ in the non-ADT group (77). The number needed to harm (ie. cause one fracture) was 28 for men receiving a GnRH agonist (77). These results are supported by a systematic review, which demonstrated that men receiving ADT had a $23 \%$ increased risk of fracture (RR 1.23, 95\% CI: 1.10-1.38) compared to non-ADT controls (82).

\subsubsection{Assessment of bone health}

All men initiating ADT therapy should be screened for osteoporosis as per the 2010 clinical practice guidelines for the diagnosis and management of osteoporosis in Canada (83). They should undergo a comprehensive history and physical examination, with a focus on falls risk and height measurements. Basic laboratory investigations include calcium and 25-Hydroxyvitamin D measurements.

All men initiating ADT should have initial BMD testing using DXA. Osteoporosis is defined as BMD of 2.5 or more standard deviations below the peak bone mass for young adults (i.e., T-score $\leq-2.5$ ). Osteopenia (low bone mass) is defined as BMD more than 1.0 but less than 2.5 standard deviations below the peak bone mass for young adults (i.e., T-score $<-1$ and $>$ $-2.5)$. Results of BMD testing, in addition to other clinical variables, should be used to calculate a patient's 10-year risk of a major osteoporotic fracture. The recommended tools for calculating fracture risk are: the Canadian Association of Radiologists and Osteoporosis Canada (CAROC; see www.osteoporosis.ca) (84) and the Fracture Risk Assessment tool (FRAX) of the World Health Organization (WHO), specific for Canada (www.sheffield.ac.uk/FRAX/tool.jsp?country=19) (85). Using these tools, patients are stratified into low $(<10 \%)$, moderate $(10-20 \%)$ or high $(>20 \%)$ risk for fractures, which allows risk stratification for consideration of pharmacological therapy (86). DXA scans should be repeated every 1-2 years or sooner for men with osteoporosis or osteopenia.

\subsubsection{Management of adverse bone effects}

All men receiving ADT should be encouraged to maintain basic bone health standards, as outlined by the Osteoporosis Canada guidelines (83). This includes adequate calcium intake (1200 mg daily total from diet and supplements) and vitamin D supplementation (800-2000 IU daily). Of note, these strategies have not been proven to decrease risk of BMD loss or fractures in men receiving ADT, but have been shown to prevent fractures in the general population over the age of 50 (87). Lifestyle modifications include smoking cessation and limited alcohol consumption, as both smoking and alcohol use are associated with bone loss and fractures (88). Exercise therapy improves multiple physical domains in men with PC receiving ADT, including preservation of muscle mass and strength, which may decrease risk of fractures (see Section on Exercise Therapy). In addition, exercise appears to preserve BMD in men receiving ADT (89) (90). 
The effect of various pharmacological therapies on BMD in men receiving ADT have been studied. Bisphosphonates (pamidronate, alendronate, risedronate and zoledronic acid) act by inhibiting osteoclast activity, which decreases bone resorption. Smith et al evaluated the role of pamidronate on bone loss in men with advanced or recurrent PC without bony metastases receiving leuprolide (91). The study found that pamidronate $(60 \mathrm{mg}$ intravenously every 12 weeks) significantly improved BMD in the hip and lumbar spine at 48 weeks following initiation of therapy. Similar findings were obtained for zoledronic acid, alendronate and risedronate in men with nonmetastatic PC (92) (93) (94). However, the impact of bisphosphonates in reducing fracture risk in men with nonmetastatic PC receiving ADT has not yet been investigated in clinical trials. Therefore, routine use of bisphosphonates in these men without other risk factors is currently not recommended. Denosumab is a human monoclonal antibody against the receptor activator of nuclear factor $\mathrm{\kappa B}$ (RANK) ligand, which mediates osteoclast differentiation and activation. It has been shown to improve BMD and decrease risk of vertebral fractures in men with nonmetastatic PC receiving ADT at high risk of fracture (95).

Both zoledronic acid and denosumab have proven to be effective in reducing SREs in men with CRPC. The role of bone-targeted agents in men with CRPC is beyond the scope of this guideline and described elsewhere (96).

Based on current guideline recommendations from Osteoporosis Canada, Cancer Care Ontario and the American Society of Clinical Oncology (83) (97) (98), combined with the above clinical trial results, the guideline committee has made recommendations on management of bone health in men receiving ADT. A summary of available pharmacological agents is listed in Table 3.

\subsection{Hot flashes}

Summary of evidence

- Hot flashes are a common and bothersome side effect of ADT.

\section{Recommendations}

- Patients should be counselled on identification and avoidance of potential triggers (Expert opinion).

- The best pharmacological therapy to treat hot flashes remains unclear, however several agents have shown to be effective and may be considered for use ( $L E: 2$, weak recommendation).

- Use of intermittent ADT improves hot flashes and should be considered in appropriately selected patients ( $L E: 2$, strong recommendation).

- Acupuncture may have a beneficial effect and can be considered in patients unwilling or unable to use pharmacotherapy (LE: 3, weak recommendation).

Vasomotor flushing or "hot flashes" occur in most men receiving ADT and are described as a sudden onset of facial sweating and discomfort. If bothersome, they can lead to a deterioration in 
HRQOL and may decrease compliance to ADT. Lifestyle modifications may be recommended, including avoidance of potential patient-identified triggers, commonly heat or spicy foods (99).

Several pharmacological agents have been assessed in the treatment of hot flashes (100) (101). Gabapentin at a dose of $900 \mathrm{mg}$ daily reduces hot flashes compared to placebo (101). The role of venlafaxine ( $75 \mathrm{mg}$ daily), medroxyprogesterone acetate (20 $\mathrm{mg}$ daily) or cyproterone acetate (100 mg daily) for reducing hot flashes in men receiving ADT was assessed in a RCT of 311 men (100). The authors found a significant decrease in frequency of hot flashes using all therapies (-47.2\% for venlafaxine, $-94.5 \%$ for cyproterone, $-83.7 \%$ for medroxyprogesterone; all $\mathrm{p}<0.001$ from baseline), however medroxyprogesterone and cyproterone appeared to be more effective than venlafaxine. Megestrol acetate has also proven to be of benefit in reducing the frequency of hot flashes in men receiving ADT (102). Common pharmacological agents used for the treatment of hot flashes are listed in Table 4.

The role of complementary medicine has been investigated for treatment of hot flashes. Of these, the most widely studied is acupuncture therapy. Acupuncture has been shown to decrease hot flash symptoms by $89-95 \%$ (103) (104), however these results are not based on RCT data. In men who do not wish to receive pharmacological therapy, acupuncture may be a reasonable option albeit based on low quality evidence.

In a RCT of continuous ADT versus intermittent ADT, men receiving intermittent therapy experienced significantly better scores for hot flashes $(\mathrm{p}<0.001)$ (105). Use of intermittent ADT is discussed in further detail in the HRQOL section of this guideline.

\subsection{Breast events}

\section{Summary of evidence}

- ADT related breast events include gynecomastia and mastodynia. Gynecomastia occurs most commonly with AA monotherapy and is a rare complication of LHRH monotherapy or combined androgen blockade.

\section{Recommendations}

- Prophylaxis for the prevention of gynecomastia in men receiving ADT is not currently recommended (Expert opinion).

- Tamoxifen or RT may be used for prevention and treatment of breast events in men receiving bicalutamide monotherapy; tamoxifen is more effective than $\mathbf{R T}$ ( $L E ~ 1$; strong recommendation).

Gynecomastia (increased amount of breast tissue) and mastodynia (breast tenderness), collectively referred to as breast events, can be bothersome side effects of ADT and may occur concurrently or separately. Gynecomastia occurs as a result of peripheral conversion of testosterone to estradiol, which increases the ratio of estrogen to androgen activity. It is more pronounced with AA monotherapy, with incidence reported as high as $85 \%$ in men taking 150 $\mathrm{mg}$ of bicalutamide (106). The incidence for patients on combined androgen blockade is lower at 
13-22\% (106). Several studies have demonstrated that both tamoxifen and radiotherapy are effective prophylactic treatments for breast events. (107) (108) (109) (110) (111) (112). RCT data suggest that tamoxifen is more effective than a single 12-Gy fraction on the day of starting bicalutamide at preventing this complication (107) (108). Once breast events occur, treatments using tamoxifen or RT have been well described (113) (107) (114) (115). Tamoxifen is more effective than a single 12-Gy fraction of RT at decreasing severity of breast events after they develop in men on bicalutamide therapy (107).

\subsection{Cognitive function}

\section{Summary of evidence}

- Use of ADT in men with PC may be associated with changes in cognition, depression and development of dementia; however, evidence related to causality remains weak and further prospective data are needed.

\section{Recommendations}

- Men receiving ADT should be monitored for cognitive decline and depression throughout duration of treatment (Expert opinion).

The effect of ADT on cognition was measured by clinical studies, both subjectively (through self-reported symptoms) and objectively (using standardized cognitive tests). Changes in cognition have been associated with receiving ADT in $25 \%$ to $50 \%$ of patients (116) (117). Selfreported cognitive changes of ADT included difficulties with concentration, information processing, verbal fluency, visual information processing, visuospatial function, memory, and executive function as well as neurofatigue and apathy. The severity of reported symptoms varied greatly from minor challenges like forgetting an item on a to-do list, to more serious effects that compromised daily functioning (116) (117). Studies that assessed cognition objectively have found men on ADT had impairments in verbal memory (118), spatial abilities (119), and attention (120). However, other studies have found no appreciable effect of ADT on cognition (116) (121) (122), or a decline for only a subset of participants (123). Some studies have even reported an improvement in verbal memory (124), or a reduced risk of dementia (125).

Furthermore, ADT may be associated with development of depressive symptoms (126). Specifically, ADT has been associated with increased rates of major depression and worsening depressive symptoms without an increased risk of suicidality (126). Several recent studies and a meta-analysis concluded that men receiving ADT are at increased risk for developing dementia and/or Alzheimer's disease compared to men with PC not receiving ADT (127). The differences in the studies' findings may reflect a variation in their methodology, including the regimen of ADT treatment (continuous or intermittent), methods (surgical or medical castration), the use of other concomitant treatments (e.g., radiation), and the nature of control groups (healthy control or men with PC not on ADT) (128) (129) (130). Given the conflicting data, RCTs in this setting are warranted. 


\subsection{Fatigue and anemia}

\section{Summary of evidence}

- Fatigue is a noticeable side effect of ADT and the underlying cause is often multifactorial. Anemia occurs commonly in men receiving ADT, but is mild in most cases and often does not warrant treatment.

\section{Recommendations}

- Men experiencing fatigue should be counselled to participate in exercise therapy ( $L E$ 2 , strong recommendation).

- Men with severe anemia or those with a decline in hemoglobin that exceeds the expected response to ADT alone should be referred for further evaluation (Expert opinion).

Fatigue is a noticeable side effect of ADT and may occur in up to $40 \%$ of men (131). The underlying mechanism likely relates to the detrimental physical effects of ADT combined with poor HRQOL in certain men. It may also be associated with depression (132). Fatigue is best treated with exercise therapy, with multiple well designed clinical trials reporting a beneficial outcome (133). Recently, Taafee et al found that various exercise regimens are effective at reducing fatigue in men receiving ADT, and that men with the highest levels of fatigue were most likely to benefit from therapy (134). Suggested exercise regimens are outlined in Section 3.1.4.

Anemia is a common side effect of ADT and is usually normocytic and normochromic (135). Most studies report a decrease in hemoglobin levels by 1 to $2 \mathrm{ng} / \mathrm{dL}$ from baseline (135), which is unlikely to cause clinically relevant outcomes. However, symptomatic anemia may be more pronounced in men with metastatic PC and pre-existing cancer associated anemia (135). The impact of anemia on fatigue in men receiving ADT remains unknown, but is a likely contributor. Treatment is rarely indicated, but may include blood transfusion and erythropoietin in severe cases. As most causes of anemia are multifactorial, patients should be investigated for common secondary underlying causes (ie. iron deficiency, vitamin B12 or folate deficiency) if the anemia is severe or the hemoglobin decreases more than what is expected for ADT alone. In these cases, referral to a hematologist may be beneficial.

\subsection{Sexual function}

\section{Summary of evidence}

- ADT impacts multiple domains of sexual function, including body image, loss of libido and erectile function.

\section{Recommendations}

- In men desiring improved sexual function, referral to a sex therapist for multimodal treatment should be considered (Expert opinion). 
- Intermittent ADT may improve libido and erectile function and should be considered in appropriately selected patients ( $L E$ 1, strong recommendation).

The effect of ADT on sexual dysfunction is profound. Multiple domains of sexual function are impacted, and include: decreased penile and testicular size, loss of libido (in up to $90 \%$ of men), decreased sensitivity to sexual stimulation, and erectile dysfunction (132). In one study, penile length decreased from an average of $10.76 \mathrm{~cm}$ to $8.05 \mathrm{~cm}$ after 15 months of ADT, and plateaued thereafter (136). Pathological studies have shown significant testicular atrophy in men receiving ADT (106). These changes, combined with alterations in weight, muscle mass and gynecomastia, may have a detrimental impact on self-perceived body image leading to poor sexual function and decreased partner intimacy.

Various interventions are available to help men improve sexual function while receiving ADT. Patients require appropriate pre-treatment counselling regarding side effects, particularly with respect to body image. Referrals to psychosocial support groups and/or sex therapists should be offered to interested patients. Erectile dysfunction may be treated with phosphodiesterase inhibitors, however treatment efficacy may be poor without adequate mental and physical arousal (137). Intermittent ADT (discussed below) has been shown to improve sexual function and should be considered in appropriate patients.

\subsection{Health-related quality of life}

\section{Summary of evidence}

- Patients on ADT experience significant decrements in multiple HRQOL domains.

\section{Recommendations}

- Exercise therapy should be encouraged in all men to improve HRQOL during treatment (LE 2, strong recommendation).

- Intermittent ADT improves HRQOL and should be considered in appropriately selected patients ( $L E 1$, strong recommendation).

\subsubsection{Impact of $A D T$ on $H R Q O L$}

The constellation of ADT-induced side effects involves multiple organ systems that have the potential to affect several functional and psychological domains. Not surprisingly, multiple HRQOL measures are impacted by hormonal therapy. Men with PC are a vulnerable population that suffer from anxiety and distress, and the addition of further HRQOL stressors secondary to ADT warrants discussion.

Several reports regarding the impact of ADT on several HRQOL measures are available. In a population based, prospective cohort study that included 1600 men with localized PC and age-matched controls, patients on ADT were more likely to experience a decline in general physical and mental health scores at three years of follow-up (138). Likewise, Fowler et al found a profound decrement on multiple HRQOL indices in men receiving ADT following radical prostatectomy, including impact of cancer and treatment, worries about cancer and dying, and 
concerns regarding body image, mental health, general health, activity and energy (139). These results are consistent with RCT data, which have consistently demonstrated a significant deterioration in sexual function in men receiving various forms of ADT (140) (141). The aforementioned studies evaluated mostly historical cohorts, but contemporary data using validated questionnaires report similar findings. Specifically, studies have found lower vitality and hormonal HRQOL scores in patients receiving neoadjuvant ADT prior to RT (142) (143). The lower vitality and hormonal scores may indicate worse hot flashes, depression, lack of energy and increased body weight. Overall, the data support a significant impact on various HRQOL measures in men with PC undergoing ADT.

\subsubsection{Exercise therapy for improving $H R Q O L$}

The impact of ADT on HRQOL may in part be mitigated by exercise therapy. This intervention has been addressed by several RCTs, most of which have shown favourable results (43) (63). Systematic reviews on this topic have also reported an improvement in many HRQOL parameters in men receiving ADT undergoing exercise therapy (144). Together, these data support exercise therapy as a reasonable strategy to offset detriments in HRQOL that occur with ADT. The duration and type of exercise for optimal benefit remains unknown, however physicians may follow published guidelines regarding exercise therapy in patients with cancer (70) (71), reviewed elsewhere in this text.

\subsubsection{Intermittent ADT}

Another strategy to reduce the impact of ADT on HRQOL is use of intermittent therapy. The Canadian PR7 trial was a RCT that compared continuous versus intermittent ADT in patients with biochemical recurrence after definitive RT and no evidence of metastases (105). There was no difference in outcomes with respect to overall survival (8.8 vs 9.1 years, HR 1.02 , 95\% CI: 0.86-1.21) between the two treatment arms. A caveat to this finding is that an unplanned subgroup analysis demonstrated worse survival in men with Gleason $>7$ on intermittent therapy. Notably, more men in the intermittent group died of disease-specific causes while men in the continuous arm experienced more non-cancer related deaths. Improvements in multiple HRQOL domains were seen in the intermittent group, including physical function, fatigue, hot flashes, urinary problems, and erectile dysfunction. Desire for sexual activity was also improved in the intermittent group.

The role of intermittent ADT in men with metastatic disease is controversial. Hussein et al performed a phase III trial in men with newly diagnosed, metastatic hormone-sensitive PC randomized to continuous versus intermittent ADT (145). The co-primary end points were noninferiority of intermittent ADT in terms of overall survival and assessment of HRQOL at 3 months following randomization. Men in the intermittent therapy arm appeared to have worse survival compared to continuous treatment, however the results were deemed to be statistically inconclusive. At 3 months following randomization, there was a statistically significant improvement in erectile dysfunction and mental health for men receiving intermittent therapy. 
Physical functioning, libido and vitality trended towards a benefit from intermittent ADT, however the results did not reach statistical significance.

Overall, the decision to proceed with intermittent or continuous ADT must be individualized to patient preferences, expectations with respect to impact of therapy on HRQOL and disease status. Appropriate counseling and shared decision-making are critical to assure an appropriate balance between favourable HRQOL outcomes and acceptable oncological control. In general, men with nonmetastatic PC are likely to benefit from intermittent ADT without major concern for compromised oncological outcomes, while those with metastatic PC should be considered for intermittent therapy with caution. The HERO trial assessing the efficacy and safety of the oral GnRH antagonist, relugolix, demonstrated substantially improved testosterone recovery in men receiving relugolix compared to leuprolide, which may have important implications for intermittent ADT and HRQOL (31). This will need to be addressed in future clinical trial settings.

\section{Conclusions and future directions}

ADT improves survival in men with PC, however it is associated with multiple adverse effects that span across multiple organ systems (Table 5). Patients require appropriate counselling regarding adverse effects, and therapy should be reserved only for patients that are likely to derive an oncological benefit. A partnership between the urologist and primary care providers using a multi-disciplinary approach is imperative to mitigate complications that may occur in response to ADT (Figure 1). This has become increasingly important in an era of rapidly emerging and effective pharmacologic therapies for advanced PC, for which ADT remains a mainstay of treatment.

COMPETING INTERESTS: Dr. So has been an advisory board member for AbbVie, Amgen, Astellas, Bayer, Janssen, Ferring, and TerSera; and has participated in clinical trials supported by Astellas, Ferring, and Janssen. Dr. Izard has received a grant(s) or honoraria from AbbVie, Astellas, Bayer, Ferring, Janssen, and Sanofi; and has participated in clinical trials supported by AbbVie, Astellas, AstraZeneca, Bayer, Janssen, and Merck. Dr. Saad has been an advisory board member for and has received payment/honoraria from AbbVie, Amgen, Astellas, Bayer, Janssen, and Sanofi; and has participated in clinical trials supported by Amgen, Astellas, Bayer, Janssen, and Sanofi. Dr. Shayegan has been an advisory board member for Astellas, Bayer, and Janssen; and has received a research grant from Janssen. Dr. Aprikian has been an advisory board member for AbbVie, Astellas, and Bayer; and has received grants from AbbVie, Astellas Bayer, Sanofi, and TerSera. Dr. Rendon has been an advisory board and speakers' bureau member for and has received honoraria from AbbVie, Amgen, Astellas, AstraZeneca, Bayer, Ferring, Jansen, and Sanofi. The remaining authors report no competing personal or financial interests related to this work. The remaining authors report no competing personal or financial interests related to this work. 


\section{References}

1. 2020., Canadian Cancer Statistics 2020. Canadian Cancer Society.

2. Canadian Cancer Society's Advisory Committee on Cancer Statistics. Canadian Cancer Statistics 2018. Toronto, ON: Canadian Cancer Society, 2018.

3. Center for Evidence-Based Medicine (CEBM), 2018. Available at: https://www.cebm.net. Accessed Feb. 13, 2021. [Online]

4. The Grading of Recommendations: Assessment, Development, and Evaluation (GRADE) working group, 2018. Available at: http://www.gradeworkinggroup.org. Accessed Feb. 12, 2021. [Online]

5. Pagliarulo V. Androgen Deprivation Therapy for Prostate Cancer. In: Schatten H, editor. Molecular \& Diagnostic Imaging in Prostate Cancer: Clinical Applications and Treatment Strategies. Cham: Springer International Publishing; 1-30., 2018.

6. Trachtenberg J, Gittleman M, Steidle C et al. A phase 3, multicenter, open label, randomized study of abarelix versus leuprolide plus daily antiandrogen in men with prostate cancer. The Journal of urology. 2002; 167(4):1670-4.

7. Chowdhury S, Robinson D, Cahill D et al. Causes of death in men with prostate cancer: an analysis of 50,000 men from the Thames Cancer Registry. BJU Int. 2013; 112(2):182-189. 8. Levine GN, D'Amico AV, Berger P, et al. Androgen-deprivation therapy in prostate cancer and cardiovascular risk: a science advisory from the American Heart Association, American Cancer Society, and American Urological Association: endorsed by the American Society for Radiation Oncology. Circulation. 2010; 121(6):833-840.

9. U.S. Food \& Drug Administration. FDA drug safety communication: update to ongoing safety review of gnrh agonists and notification to manufacturers of gnrh agonists to add new safety information to labeling regarding increased risk of diabetes and certain cardiovascular diseases. [Online] 2010. https://www.fda.gov/Drugs/DrugSafety/ ucm229986.htm.

10. GnRH Agonists: Heart-related Risk in Men Treated for Prostate Cancer. [Online] 2011. https://www.healthycanadians.gc.ca/recall-alert-rappel-avis/hc-sc/2011/13541a-eng.php.

11. Saigal CS, Gore JL, Krupski TL, et al. Androgen deprivation therapy increases cardiovascular morbidity in men with prostate cancer. Cancer. 2007; 110(7):1493-1500.

12. Keating NL, O'Malley AJ, Smith MR. Diabetes and cardiovascular disease during androgen deprivation therapy for prostate cancer. J Clin Oncol. 2006; 24(27):4448-4456.

13. Keating NL, O'Malley A, Freedland SJ, Smith MR. Diabetes and cardiovascular disease during androgen deprivation therapy: observational study of veterans with prostate cancer. J Natl Cancer Inst. 2012; 104(19):1518-1523.

14. Wirth MP, See WA, McLeod DG, et al. Bicalutamide $150 \mathrm{mg}$ in addition to standard care in patients with localized or locally advanced prostate cancer: results from the second analysis of the early prostate cancer program at median followup of 5.4 years. J Urol. 2004; 172:1865-1870. 
15. Jespersen CG, Nørgaard M, Borre M. Androgen-deprivation therapy in treatment of prostate cancer and risk of myocardial infarction and stroke: a nationwide Danish population-based cohort study. Eur Urol. 2014; 65(4):704-709.

16. Roach M 3rd, Bae K, Speight J, et al. Short-term neoadjuvant androgen deprivation therapy and external-beam radiotherapy for locally advanced prostate cancer: long-term results of RTOG 8610. J Clin Oncol. 2008; 26(4):585-591.

17. Efstathiou JA, Bae K, Shipley WU, et al. Cardiovascular mortality after androgen deprivation therapy for locally advanced prostate cancer: RTOG 85-31. J Clin Oncol. 2009; 27(1):92-99.

18. Voog JC, Paulus R, Shipley WU, et al. Cardiovascular Mortality Following Short-term Androgen Deprivation in Clinically Localized Prostate Cancer: An Analysis of RTOG 94-08. Eur Urol. 2016; 69(2):204-210.

19. D'Amico AV, Denham JW, Crook J, et al. Influence of androgen suppression therapy for prostate cancer on the frequency and timing of fatal myocardial infarctions. J Clin Oncol. 2007; 25(17):2420-2425.

20. Zhao J, Zhu S, Sun L, et al. Androgen deprivation therapy for prostate cancer is associated with cardiovascular morbidity and mortality: a meta-analysis of population-based observational studies. PLoS One. 2014; 9(9):e107516.

21. Bosco C, Bosnyak Z, Malmberg A, Adolfsson J, Keating NL, Van Hemelrijck M. Quantifying observational evidence for risk of fatal and nonfatal cardiovascular disease following androgen deprivation therapy for prostate cancer: a meta-analysis. Eur Urol. 2015;68(3):386-396.

22. Nguyen PL, Je Y, Schutz FA, et al. Association of androgen deprivation therapy with cardiovascular death in patients with prostate cancer: a meta-analysis of randomized trials. JAMA. 2011;306(21):2359-2366.

23. O'Farrell S, Garmo H, Holmberg L, Adolfsson J, Stattin P, Van Hemelrijck M. Risk and timing of cardiovascular disease after androgen-deprivation therapy in men with prostate cancer. J Clin Oncol. 2015;33(11):1243-1251.

24. Ziehr DR, Chen MH, Zhang D, et al. Association of androgen-deprivation therapy with excess cardiac-specific mortality in men with prostate cancer. BJU Int. 2015;116(3):358-365. 25. Nanda A, Chen MH, Braccioforte MH, Moran BJ, D'Amico AV. Hormonal therapy use for prostate cancer and mortality in men with coronary artery disease-induced congestive heart failure or myocardial infarction. JAMA. 2009;302(8):866-873.

26. Knutsson A, Hsiung S, Celik S, et al. Treatment with a GnRH receptor agonist, but not the $\mathrm{GnRH}$ receptor antagonist degarelix, induces atherosclerotic plaque instability in ApoE(-/-) mice. Sci Rep 2016;6:26220.

27. Hopmans SN, Duivenvoorden WC, Werstuck GH, et al. GnRH antagonist associates with less adiposity and reduced characteristics of metabolic syndrome and atherosclerosis compared with orchiectomy and GnRH agonist in a preclinical mouse model. Urol Oncol 2014;32:1126-34. 
28. Albertsen PC, Klotz L, Tombal B, Grady J, Olesen TK, Nilsson J. Cardiovascular morbidity associated with gonadotropin releasing hormone agonists and an antagonist. Eur Urol. 2014;65(3):565-573.

29. Margel D, Peer A, Ber Y, et al. Cardiovascular Morbidity in a Randomized Trial Comparing GnRH Agonist and GnRH Antagonist among Patients with Advanced Prostate Cancer and Preexisting Cardiovascular Disease. J Urol. 2019;202(6):1199-1208.

30. Scailteux LM, Vincendeau S, Balusson F, et al. Androgen deprivation therapy and cardiovascular risk: No meaningful difference between GnRH antagonist and agonists-a nationwide population-based cohort study based on 2010-2013 French Health Insurance data. Eur J Cancer. 2017;77:99-108.

31. Shore ND, Saad F, Cookson MS, et al. Oral Relugolix for Androgen-Deprivation Therapy in Advanced Prostate Cancer. N Engl J Med. 2020; 382(23):2187-2196.

32. Ehdaie B, Atoria CL, Gupta A, et al. Androgen deprivation and thromboembolic events in men with prostate cancer. Cancer. 2012;118(13):3397-3406.

33. Klil-Drori AJ, Yin H, Tagalakis V, Aprikian A, Azoulay L. Androgen deprivation therapy for prostate cancer and the risk of venous thromboembolism. Eur Urol. 2016;70(1):56-61.

34. Guo Z, Huang Y, Gong L, et al. Association of androgen deprivation therapy with thromboembolic events in patients with prostate cancer: a systematic review and meta-analysis. Prostate Cancer Prostatic Dis. 2018;21(4):451-460.

35. Nead KT, Boldbaatar N, Yang DD, Sinha S, Nguyen PL. Association of Androgen Deprivation Therapy and Thromboembolic Events: A Systematic Review and Meta-analysis. Urology. 2018;114:155-162.

36. Smith MR, Finkelstein JS, McGovern FJ, et al. Changes in body composition during androgen deprivation therapy for prostate cancer. J Clin Endocrinol Metab. 2002;87(2):599-603. 37. Berruti A, Dogliotti L, Terrone C, et al. Changes in bone mineral density, lean body mass and fat content as measured by dual energy $\mathrm{x}$-ray absorptiometry in patients with prostate cancer without apparent bone metastases given androgen deprivation therapy. J Urol. 2002;167(6):23612367.

38. Smith MR. Changes in fat and lean body mass during androgen-deprivation therapy for prostate cancer. Urology. 2004;63(4):742-745.

39. Haseen F, Murray LJ, Cardwell CR, O'Sullivan JM, Cantwell MM. The effect of androgen deprivation therapy on body composition in men with prostate cancer: systematic review and meta-analysis. J Cancer Surviv. 2010;4(2):128-139.

40. Cheung AS, Tinson AJ, Milevski SV, Hoermann R, Zajac JD, Grossmann M. Persisting adverse body composition changes 2 years after cessation of androgen deprivation therapy for localised prostate cancer. Eur J Endocrinol. 2018;179(1):21-29.

41. Spry NA, Taaffe DR, England PJ, et al. Long-term effects of intermittent androgen suppression therapy on lean and fat mass: a 33-month prospective study. Prostate Cancer Prostatic Dis. 2013;16(1):67-72. 
42. Storer TW, Miciek R, Travison TG. Muscle function, physical performance and body composition changes in men with prostate cancer undergoing androgen deprivation therapy. Asian J Androl. 2012;14(2):204-221.

43. Cormie P, Zopf EM. Exercise medicine for the management of androgen deprivation therapy-related side effects in prostate cancer. Urol Oncol. 2020;38(2):62-70.

44. Bylow K, Dale W, Mustian K, et al. Falls and physical performance deficits in older patients with prostate cancer undergoing androgen deprivation therapy. Urology. 2008;72(2):422-427. 45. Calle EE, Rodriguez C, Walker-Thurmond K, Thun MJ. Overweight, obesity, and mortality from cancer in a prospectively studied cohort of U.S. adults. N Engl J Med. 2003;348(17):16251638 .

46. Efstathiou JA, Bae K, Shipley WU, et al. Obesity and mortality in men with locally advanced prostate cancer: analysis of RTOG 85-31. Cancer. 2007;110(12):2691-2699.

47. Gong Z, Agalliu I, Lin DW, Stanford JL, Kristal AR. Obesity is associated with increased risks of prostate cancer metastasis and death after initial cancer diagnosis in middle-aged men. Cancer. 2007;109(6):1192-1202.

48. Keto CJ, Aronson WJ, Terris MK, et al. Obesity is associated with castration-resistant disease and metastasis in men treated with androgen deprivation therapy after radical prostatectomy: results from the SEARCH database. BJU Int. 2012;110(4):492-498.

49. Smith MR, Lee H, Nathan DM. Insulin sensitivity during combined androgen blockade for prostate cancer. J Clin Endocrinol Metab. 2006;91(4):1305-1308.

50. Basaria S, Muller DC, Carducci MA, Egan J, Dobs AS. Hyperglycemia and insulin resistance in men with prostate carcinoma who receive androgen-deprivation therapy. Cancer. 2006;106(3):581-588.

51. Alibhai SM, Duong-Hua M, Sutradhar R, et al. Impact of androgen deprivation therapy on cardiovascular disease and diabetes. J Clin Oncol. 2009;27(21):3452-3458.

52. Haidar A, Yassin A, Saad F, Shabsigh R. Effects of androgen deprivation on glycaemic control and on cardiovascular biochemical risk factors in men with advanced prostate cancer with diabetes. Aging Male. 2007;10(4):189-196.

53. Smith MR, Lee H, McGovern F, et al. Metabolic changes during gonadotropin-releasing hormone agonist therapy for prostate cancer: differences from the classic metabolic syndrome. Cancer. 2008;112(10):2188-2194.

54. Yannucci J, Manola J, Garnick MB, Bhat G, Bubley GJ. The effect of androgen deprivation therapy on fasting serum lipid and glucose parameters. J Urol. 2006;176(2):520-525.

55. Bagatell CJ, Knopp RH, Vale WW, Rivier JE, Bremner WJ. Physiologic testosterone levels in normal men suppress high-density lipoprotein cholesterol levels. Ann Intern Med. 1992;116(12 Pt 1):967-973.

56. Eri LM, Urdal P, Bechensteen AG. Effects of the luteinizing hormone-releasing hormone agonist leuprolide on lipoproteins, fibrinogen and plasminogen activator inhibitor in patients with benign prostatic hyperplasia. J Urol. 1995;154(1):100-104. 
57. Smith MR, Malkowicz SB, Chu F, et al. Toremifene improves lipid profiles in men receiving androgen-deprivation therapy for prostate cancer: interim analysis of a multicenter phase III study. J Clin Oncol. 2008;26(11):1824-1829.

58. Braga-Basaria M, Dobs AS, Muller DC, et al. Metabolic syndrome in men with prostate cancer undergoing long-term androgen-deprivation therapy. J Clin Oncol. 2006;24(24):39793983.

59. Alberti KG, Eckel RH, Grundy SM, et al. Harmonizing the metabolic syndrome: a joint interim statement of the International Diabetes Federation Task Force on Epidemiology and Prevention; National Heart, Lung, and Blood Institute; American Heart Association; World Heart Federation; International Atherosclerosis Society; and International Association for the Study of Obesity. Circulation. 2009;120(16):1640-1645.

60. Nobes JP, Langley SE, Klopper T, et al. A prospective, randomized pilot study evaluating the effects of metformin and lifestyle intervention on patients with prostate cancer receiving androgen deprivation therapy. BJU Int. 2012;109(10):1495-1502.

61. Tobe SW, Stone JA, Anderson T, et al. Canadian Cardiovascular Harmonized National Guidelines Endeavour (C-CHANGE) guideline for the prevention and management of cardiovascular disease in primary care: 2018 update. CMAJ. 2018;190(40):E1192-E1206. 62.Pearson GJ, Thanassoulis G, Anderson TJ, et al. 2021 Canadian Cardiovascular Society Guidelines for the Management of Dyslipidemia for the Prevention of Cardiovascular Disease in the Adult [published online ahead of print, 2021 Mar 26]. Can J Cardiol. 2021;S0828282X(21)00165-3..

63. Gardner JR, Livingston PM, Fraser SF. Effects of exercise on treatment-related adverse effects for patients with prostate cancer receiving androgen-deprivation therapy: a systematic review. J Clin Oncol. 2014;32(4):335-346.

64. Hanson ED, Sheaff AK, Sood S, et al. Strength training induces muscle hypertrophy and functional gains in black prostate cancer patients despite androgen deprivation therapy. $\mathbf{J}$ Gerontol A Biol Sci Med Sci. 2013;68(4):490-498.

65. Galvão DA, Nosaka K, Taaffe DR, et al. Resistance training and reduction of treatment side effects in prostate cancer patients. Med Sci Sports Exerc. 2006;38(12):2045-2052.

66. Taaffe DR, Newton RU, Spry N, Joseph DJ, Galvão DA. Responsiveness to ResistanceBased Multimodal Exercise Among Men With Prostate Cancer Receiving Androgen Deprivation Therapy. J Natl Compr Canc Netw. 2019;17(10):1211-1220.

67. Cormie P, Galvão DA, Spry N, et al. Can supervised exercise prevent treatment toxicity in patients with prostate cancer initiating androgen-deprivation therapy: a randomised controlled trial. BJU Int. 2015;115(2):256-266.

68. Galvão DA, Spry N, Denham J, et al. A multicentre year-long randomised controlled trial of exercise training targeting physical functioning in men with prostate cancer previously treated with androgen suppression and radiation from TROG 03.04 RADAR. Eur Urol. 2014;65(5):856864. 
69. Gilbert SE, Tew GA, Fairhurst C, et al. Effects of a lifestyle intervention on endothelial function in men on long-term androgen deprivation therapy for prostate cancer. $\mathrm{Br} \mathrm{J}$ Cancer. 2016;114(4):401-408.

70. Campbell KL, Winters-Stone KM, Wiskemann J, et al. Exercise Guidelines for Cancer Survivors: Consensus Statement from International Multidisciplinary Roundtable. Med Sci Sports Exerc. 2019;51(11):2375-2390.

71. Segal R, Zwaal C, Green E, et al. Exercise for people with cancer: a clinical practice guideline. Curr Oncol. 2017;24(1):40-46.

72. Panju AH, Breunis H, Cheung AM, et al. Management of decreased bone mineral density in men starting androgen-deprivation therapy for prostate cancer. BJU Int 2009; 103: 753-757. 73. Wadhwa VK, Weston R, Mistry R, Parr NJ. Long-term changes in bone mineral density and predicted fracture risk in patients receiving androgendeprivation therapy for prostate cancer, with stratification of treatment based on presenting values. BJU Int 2009; 104: 800-805.

74. Grossmann M, Hamilton EJ, Gilfillan C, Bolton D, Joon DL, Zajac JD. Bone and metabolic health in patients with non-metastatic prostate cancer who are receiving androgen deprivation therapy. Med J Aust. 2011; 194(6):301-306.

75. Daniell HW, Dunn SR, Ferguson DW, Lomas G, Niazi Z, Stratte PT. Progressive osteoporosis during androgen deprivation therapy for prostate cancer. J Urol. 2000; 163(1):181186.

76. Maillefert JF, Sibilia J, Michel F, Saussine C, Javier RM, Tavernier C. Bone mineral density in men treated with synthetic gonadotropin-releasing hormone agonists for prostatic carcinoma. J Urol. 1999; 161(4):1219-1222.

77. Shahinian VB, Kuo YF, Freeman JL, et al. Risk of fracture after androgen deprivation for prostate cancer. N Engl J Med 2005; 352:154-64.

78. Greenspan SL, Coates P, Sereika SM et al. Bone Loss after Initiation of Androgen Deprivation Therapy in Patients with Prostate Cancer. J Clin Endo Metab 2005: 90 (12); 64106417.

79. Morote J, Orsola A, Abascal JM, et al. Bone mineral density changes in patients with prostate cancer during the first 2 years of androgen suppression. J Urol 2006; 175: 1679-1683. 80. Smith MR, Lee WC, Brandman J, et al. Gonadotropin-releasing hormone agonists and fracture risk: a claims-based cohort study of men with nonmetastatic prostate cancer. J Clin Oncol 2005; 23:7897-903.

81. Smith MR, Boyce SP, Moyneur E, Duh MS, Raut MK, Brandman J. Risk of clinical fractures after gonadotropin-releasing hormone agonist therapy for prostate cancer. J Urol. 2006; 175(1):136-139.

82. Taylor LG, Canfield SE, Du XL. Review of major adverse effects of androgen-deprivation therapy in men with prostate cancer. Cancer. 2009; 115(11):2388-2399.

83. Papaioannou A, Morin S, Cheung AM, et al. 2010 clinical practice guidelines for the diagnosis and management of osteoporosis in Canada: summary. CMAJ. 2010; 182(17):18641873 . 
84. Leslie WD, Berger C, Langsetmo L, et al. Construction and validation of a simplified fracture risk assessment tool for Canadian women and men: results from the CaMos and Manitoba cohorts. Osteoporos Int. 2011; 22(6):1873-1883.

85. Leslie WD, Lix LM, Langsetmo L, et al. Construction of a FRAX® model for the assessment of fracture probability in Canada and implications for treatment. Osteoporos Int. 2011; 22(3):817-827.

86. Siminoski K, Leslie WD, Frame H, et al. Recommendations for bone mineral density reporting in Canada. Can Assoc Radiol J. 2005;56(3):178-188.

87. Tang BM, Eslick GD, Nowson C, Smith C, Bensoussan A. Use of calcium or calcium in combination with vitamin D supplementation to prevent fractures and bone loss in people aged 50 years and older: a meta-analysis [published correction appears in Lancet. 2012 Sep 1; 2007, 380(9844):806]. Lancet.; 370(9588):657-666.

88. Lee CE, Leslie WD, Czaykowski P, Gingerich J, Geirnaert M, Lau YK. A comprehensive bone-health management approach for men with prostate cancer receiving androgen deprivation therapy. Curr Oncol. 2011 and 18(4):e163-e172.

89. Taaffe DR, Galvão DA, Spry N, et al. Immediate versus delayed exercise in men initiating androgen deprivation: effects on bone density and soft tissue composition. BJU Int. 2019; 123(2):261-269.

90. Newton RU, Galvão DA, Spry N, et al. Exercise Mode Specificity for Preserving Spine and Hip Bone Mineral Density in Prostate Cancer Patients. Med Sci Sports Exerc. 2019; 51(4):607614.

91. Smith MR, McGovern FJ, Zietman AL, et al. Pamidronate to prevent bone loss during androgen-deprivation therapy for prostate cancer. N Engl J Med. 2001 and 345(13):948-955. 92. Smith MR, Eastham J, Gleason DM, Shasha D, Tchekmedyian S, Zinner N. Randomized controlled trial of zoledronic acid to prevent bone loss in men receiving androgen deprivation therapy for nonmetastatic prostate cancer. J Urol. 2003 and 169(6):2008-2012.

93. Greenspan SL, Nelson JB, Trump DL, Resnick NM. Effect of once-weekly oral alendronate on bone loss in men receiving androgen deprivation therapy for prostate cancer: a randomized trial. Ann Intern Med. 2007 and 146(6):416-424.

94. Ishizaka K, Machida T, Kobayashi S, Kanbe N, Kitahara S, Yoshida K. Preventive effect of risedronate on bone loss in men receiving androgen-deprivation therapy for prostate cancer. Int $\mathrm{J}$ Urol. 2007 and 14(12):1071-1075.

95. Smith MR, Egerdie B, Hernández Toriz N, et al. Denosumab in men receiving androgendeprivation therapy for prostate cancer. N Engl J Med. 2009; 361(8):745-755.

96. Saad F, Aprikian A, Finelli A, et al. 2021 Canadian Urological Association (CUA)-Canadian Uro Oncology Group (CUOG) guideline: Management of castration-resistant prostate cancer (CRPC). Can Urol Assoc J. 2021;15(2):E81-E90.

97. Alibhai SMH, Zukotynski K, Walker-Dilks C, et al. Bone Health and Bone-targeted Therapies for Prostate Cancer: a Programme in Evidence-based Care - Cancer Care Ontario Clinical Practice Guideline. Clin Oncol (R Coll Radiol). 2017;29(6):348-355. 
98. Saylor PJ, Rumble RB, Michalski JM. Bone Health and Bone-Targeted Therapies for Prostate Cancer: American Society of Clinical Oncology Endorsement Summary of a Cancer Care Ontario Guideline. JCO Oncol Pract. 2020;16(7):389-393.

99. Rhee $\mathrm{H}$, Gunter JH, Heathcote P, et al. Adverse effects of androgen-deprivation therapy in prostate cancer and their management. BJU Int. 2015;115 Suppl 5:3-13.

100. Irani J, Salomon L, Oba R, Bouchard P, Mottet N. Efficacy of venlafaxine, medroxyprogesterone acetate, and cyproterone acetate for the treatment of vasomotor hot flushes in men taking gonadotropin-releasing hormone analogues for prostate cancer: a double-blind, randomised trial. Lancet Oncol. 2010;11(2):147-54.

101. Loprinzi CL, Dueck AC, Khoyratty BS, Barton DL, Jafar S, Rowland KM, Jr., et al. A phase III randomized, double-blind, placebo-controlled trial of gabapentin in the management of hot flashes in men (NO0CB). Ann Oncol. 2009;20(3):542-9.

102. Loprinzi CL, Michalak JC, Quella SK, et al. Megestrol acetate for the prevention of hot flashes. N Engl J Med. 1994;331(6):347-352.

103. Harding C, Harris A, Chadwick D. Auricular acupuncture: a novel treatment for vasomotor symptoms associated with luteinizing-hormone releasing hormone agonist treatment for prostate cancer. BJU Int. 2009;103(2):186-190.

104. Ashamalla H, Jiang ML, Guirguis A, Peluso F, Ashamalla M. Acupuncture for the alleviation of hot flashes in men treated with androgen ablation therapy. Int J Radiat Oncol Biol Phys. 2011;79(5):1358-1363.

105. Crook JM, O'Callaghan CJ, Duncan G, et al. Intermittent androgen suppression for rising PSA level after radiotherapy [published correction appears in N Engl J Med. 2012 Dec 6;367(23):2262]. N Engl J Med. 2012;367(10):895-903.

106. Nguyen PL, Alibhai SM, Basaria S, et al. Adverse effects of androgen deprivation therapy and strategies to mitigate them. Eur Urol. 2015;67(5):825-836.

107. Perdonà $S$, Autorino R, De Placido $S$, et al. Efficacy of tamoxifen and radiotherapy for prevention and treatment of gynaecomastia and breast pain caused by bicalutamide in prostate cancer: a randomised controlled trial. Lancet Oncol. 2005;6(5):295-300.

108. Di Lorenzo G, Perdonà S, De Placido S, et al. Gynecomastia and breast pain induced by adjuvant therapy with bicalutamide after radical prostatectomy in patients with prostate cancer: the role of tamoxifen and radiotherapy. J Urol. 2005;174(6):2197-2203.

109. Boccardo F, Rubagotti A, Battaglia M, et al. Evaluation of tamoxifen and anastrozole in the prevention of gynecomastia and breast pain induced by bicalutamide monotherapy of prostate cancer. J Clin Oncol. 2005;23(4):808-815.

110. Serretta V, Altieri V, Morgia G, et al. A randomized trial comparing tamoxifen therapy vs. tamoxifen prophylaxis in bicalutamide-induced gynecomastia. Clin Genitourin Cancer. 2012;10(3):174-179.

111. Widmark A, Fosså SD, Lundmo $\mathrm{P}$, et al. Does prophylactic breast irradiation prevent antiandrogen-induced gynecomastia? Evaluation of 253 patients in the randomized Scandinavian trial SPCG-7/SFUO-3. Urology. 2003;61(1):145-151. 
112. Tyrrell CJ, Payne H, Tammela TL, et al. Prophylactic breast irradiation with a single dose of electron beam radiotherapy ( $10 \mathrm{~Gy}$ ) significantly reduces the incidence of bicalutamideinduced gynecomastia. Int J Radiat Oncol Biol Phys. 2004;60(2):476-483.

113. Di Lorenzo G, Autorino R, Perdonà S, De Placido S. Management of gynaecomastia in patients with prostate cancer: a systematic review. Lancet Oncol. 2005;6(12):972-979.

114. Fagerlund A, Cormio L, Palangi L, et al. Gynecomastia in Patients with Prostate Cancer: A Systematic Review. PLoS One. 2015;10(8):e0136094.

115. Van Poppel H, Tyrrell CJ, Haustermans K, et al. Efficacy and tolerability of radiotherapy as treatment for bicalutamide-induced gynaecomastia and breast pain in prostate cancer. Eur Urol. 2005;47(5):587-592.

116. Wu LM, Tanenbaum ML, Dijkers MPJM, Amidi A, Hall SJ, Penedo FJ, et al. Cognitive and neurobehavioral symptoms in patients with non-metastatic prostate cancer treated with androgen deprivation therapy or observation: A mixed methods study. Social Science \& Medicine. 2016;156:80-9.

117. Wu LM, Diefenbach MA, Gordon WA, Cantor JB, Cherrier MM. Cognitive problems in patients on androgen deprivation therapy: A qualitative pilot study. Urologic Oncology: Seminars and Original Investigations. 2013;31(8):1533-8.

118. Beer TM, Bland LB, Bussiere JR, Neiss MB, Wersinger EM, Garzotto M, et al. Testosterone Loss and Estradiol Administration Modify Memory in Men. J Urol 2006;175(1):130-5.

119. Cherrier MM, Aubin S, Higano CS. Cognitive and mood changes in men undergoing intermittent combined androgen blockade for non-metastatic prostate cancer. Psycho-Oncol. 2009;18(3):237-47.

120. Salminen EK, Portin RI, Koskinen A, Helenius H, Nurmi M. Associations between Serum Testosterone Fall and Cognitive Function in Prostate Cancer Patients. Clin Can Res. 2004;10(22):7575-82.

121. Alibhai SMH, Timilshina N, Duff-Canning S, Breunis H, Tannock IF, Naglie G, et al. Effects of long-term androgen deprivation therapy on cognitive function over 36 months in men with prostate cancer. Cancer. 2017;123(2):237-44.

122. Alibhai SMH, Mahmoud S, Hussain F, Naglie G, Tannock I, Tomlinson G, et al. Levels of sex hormones have limited effect on cognition in older men with or without prostate cancer. Crit Rev Oncol Hematol. 2010;73(2):167-75.

123. Morote J, Tabernero ÁJ, Álvarez Ossorio JL, Ciria JP, Domínguez-Escrig JL, Vázquez F, et al. Cognitive Function in Patients With Prostate Cancer Receiving Luteinizing HormoneReleasing Hormone Analogues: A Prospective, Observational, Multicenter Study. Int J Rad Onc Bio Phys. 2017;98(3):590-4.

124. Salminen E, Portin R, Korpela J, Backman H, Parvinen LM, Helenius H, et al. Androgen deprivation and cognition in prostate cancer. Br J Cancer. 2003;89(6):971-6. 
125. Hong J, Liao C, Huang C, Lu Y. Chemical castration decreased the risk of dementia in patients with prostate cancer - from 13368 patients, Taiwan National Health Insurance Research Database. Eur Urol Suppl. 2017;16(3):e86.

126. Siebert AL, Lapping-Carr L, Morgans AK. Neuropsychiatric Impact of Androgen Deprivation Therapy in Patients with Prostate Cancer: Current Evidence and Recommendations for the Clinician. Eur Urol Focus. 2020;6(6):1170-1179.

127. Sari Motlagh R, Quhal F, Mori K, et al. The Risk of New Onset Dementia and/or Alzheimer Disease among Patients with Prostate Cancer Treated with Androgen Deprivation Therapy: A Systematic Review and Meta-Analysis. J Urol. 2021;205(1):60-67.

128. Treanor CJ, Li J, Donnelly M. Cognitive impairment among prostate cancer patients: An overview of reviews. European Journal of Cancer Care. 2017;26(6):e12642.

129. Jamadar RJ, Winters MJ, Maki PM. Cognitive changes associated with ADT: a review of the literature. Asian journal of andrology. 2012;14(2):232-8.

130. McGinty HL, Phillips KM, Jim HSL, Cessna JM, Asvat Y, Cases MG, et al. Cognitive functioning in men receiving androgen deprivation therapy for prostate cancer: a systematic review and meta-analysis. Supportive Care in Cancer. 2014;22(8):2271-80.

131. Storey DJ, McLaren DB, Atkinson MA, et al. Clinically relevant fatigue in men with hormone-sensitive prostate cancer on long-term androgen deprivation therapy. Ann Oncol. 2012;23(6):1542-1549.

132. Higano CS. Sexuality and intimacy after definitive treatment and subsequent androgen deprivation therapy for prostate cancer [published correction appears in J Clin Oncol. $2013 \mathrm{Feb}$ 20;31(6):824]. J Clin Oncol. 2012;30(30):3720-3725.

133. Baumann FT, Zopf EM, Bloch W. Clinical exercise interventions in prostate cancer patients--a systematic review of randomized controlled trials. Support Care Cancer. 2012;20(2):221-233.

134. Taaffe DR, Newton RU, Spry N, et al. Effects of Different Exercise Modalities on Fatigue in Prostate Cancer Patients Undergoing Androgen Deprivation Therapy: A Year-long Randomised Controlled Trial. Eur Urol. 2017;72(2):293-299.

135. Grossmann M, Zajac JD. Hematological changes during androgen deprivation therapy. Asian J Androl. 2012;14(2):187-192.

136. Park KK, Lee SH, Chung BH. The effects of long-term androgen deprivation therapy on penile length in patients with prostate cancer: a single-center, prospective, open-label, observational study. J Sex Med. 2011;8(11):3214-3219.

137. Elliott S, Latini DM, Walker LM, Wassersug R, Robinson JW; ADT Survivorship Working Group. Androgen deprivation therapy for prostate cancer: recommendations to improve patient and partner quality of life. J Sex Med. 2010;7(9):2996-3010.

138. Quality of life three years after diagnosis of localised prostate cancer: population based cohort study. Smith DP, King MT, Egger S et al. 2009, BMJ, Vol. 339, p. b4817. 
139. The impact of androgen deprivation on quality of life after radical prostatectomy for prostate carcinoma. Fowler FJ Jr, McNaughton Collins M, Walker Corkery E et al. 2002, Cancer, Vol. 95, pp. 287-95.

140. Quality of life compared during pharmacological treatments and clinical monitoring for non-localized prostate cancer: a randomized controlled trial. Green HJ, Pakenham KI, Headley BC et al. 2004, BJU Int, Vol. 93, pp. 975-9.

141. Prostate cancer treated by anti-androgens. is sexual function preserved? EORTC Genitourinary Group. European Organization for Research and Treatment of Cancer. chroder FH, Collette L, De Reijke TM et al. 2000, Br J Cancer, Vol. 82, pp. 283-90.

142. Chen MC, Kilday PS, Elliott PA, et al. Neoadjuvant Leuprolide Therapy with Radical Prostatectomy: Long-term Effects on Health-related Quality of Life [published online ahead of print, 2020 Mar 9]. Eur Urol Focus. 2020.

143. Okamoto K, Sekine Y, Nomura M, et al. Effects of a luteinizing hormone-releasing hormone agonist on cognitive, sexual, and hormonal functions in patients with prostate cancer: relationship with testicular and adrenal androgen levels. Basic Clin Androl. 2015;25:3. 144. Gardner JR, Livingston PM, Fraser SF. Effects of exercise on treatment-related adverse effects for patients with prostate cancer receiving androgen-deprivation therapy: a systematic review. J Clin Oncol. 2014;32(4):335-346.

145. Hussain M, Tangen CM, Berry DL, et al. Intermittent versus continuous androgen deprivation in prostate cancer. N Engl J Med. 2013;368(14):1314-1325.

146. Smith MR, Halabi S, Ryan CJ, et al. Randomized controlled trial of early zoledronic acid in men with castration-sensitive prostate cancer and bone metastases: results of CALGB 90202 (alliance). J Clin Oncol. 2014 and 32(11):1143-1150.

147. James ND, Sydes MR, Clarke NW, et al. Addition of docetaxel, zoledronic acid, or both to first-line long-term hormone therapy in prostate cancer (STAMPEDE): survival results from an adaptive, multiarm, multistage, platform randomised controlled trial. Lancet. 2016 and 387(10024):1163-1177.

148. Seidenfeld J, Samson DJ, Hasselblad V et al. Single-therapy androgen suppression in men with advanced prostate cancer: a systematic review and meta-analysis. Annals of internal medicine. 2000; 132(7):566-77.

149. Scher HI, Morris MJ, Stadler WM, et al. Trial Design and Objectives for CastrationResistant Prostate Cancer: Updated Recommendations From the Prostate Cancer Clinical Trials Working Group 3. J Clin Oncol. 2016; 34(12):1402-1418.

150. Klotz L, Shayegan B, Guillemette C, et al. Testosterone suppression in the treatment of recurrent or metastatic prostate cancer - A Canadian consensus statement. Can Urol Assoc J. 2018; 12(2):30-37.

151. Shore ND, Antonarakis ES, Cookson MS et al. Optimizing the role of androgen deprivation therapy in advanced prostate cancer: Challenges beyond the guidelines. The Prostate. 2020; 80(6):527-44. 
152. Potosky AL, Knopf K, Clegg LX et al. Quality-of-life outcomes after primary androgen deprivation therapy: results from the Prostate Cancer Outcomes Study. Journal of clinical oncology : official journal of the American Society of Clinical Oncology. 2001; 19(17):3750-7. 153. Lepor H, Shore ND. LHRH Agonists for the Treatment of Prostate Cancer: 2012. Reviews in urology. 2012; 14(1-2):1-12.

154. Bubley GJ. Is the flare phenomenon clinically significant? Urology.; 2001; 58:5-9. 155. Crawford ED, Heidenreich A, Lawrentschuk N et al. Androgen-targeted therapy in men with prostate cancer: evolving practice and future considerations. Prostate cancer and prostatic diseases. 2019; 22(1):24-38.

156. Smith MR, Klotz L, van der Meulen E et al. Gonadotropin-releasing hormone blockers and cardiovascular disease risk: analysis of prospective clinical trials of degarelix. The Journal of urology. 2011; 186(5):1835-42.

157. Saad F, Aprikian A, Finelli A, et al. 2019 Canadian Urological Association (CUA)Canadian Uro Oncology Group (CUOG) guideline: Management of castration-resistant prostate cancer (CRPC). Can Urol Assoc J. 2019; 13(10):307-314.

158. So AI, Chi KN, Danielson B, et al. Canadian Urological Association-Canadian Urologic Oncology Group guideline on metastatic castration-naive and castration-sensitive prostate cancer. Can Urol Assoc J. 2020; 14(2):17-23.

159. Kirlangic OF, Yilmaz-Oral D, Kaya-Sezginer E, et al. The Effects of Androgens on Cardiometabolic Syndrome: Current Therapeutic Concepts. Sex Med. 2020; 8(2):132-155. 160. Jones RD, Pugh PJ, Jones TH, Channer KS. The vasodilatory action of testosterone: a potassium-channel opening or a calcium antagonistic action?. Br J Pharmacol. 2003; 138(5):733744.

161. Alexandersen P, Haarbo J, Byrjalsen I, Lawaetz H, Christiansen C. Natural androgens inhibit male atherosclerosis: a study in castrated, cholesterol-fed rabbits. Circ Res. 1999; 84(7):813-819.

162. Larsen BA, Nordestgaard BG, Stender S, Kjeldsen K. Effect of testosterone on atherogenesis in cholesterol-fed rabbits with similar plasma cholesterol levels. Atherosclerosis. 1993; 99(1):79-86.

163. Saad F, Gleason DM, Murray R, et al. Long-term efficacy of zoledronic acid for the prevention of skeletal complications in patients with metastatic hormone-refractory prostate cancer. J Natl Cancer Inst. 2004; 96(11):879-882.

164. Fizazi K, Carducci M, Smith M, et al. Denosumab versus zoledronic acid for treatment of bone metastases in men with castration-resistant prostate cancer: a randomised, double-blind study. Lancet. 2011; 377(9768):813-822.

165. Braunstein GD, Anawalt BD. Clinical features, diagnosis, and evaluation of gynecomastia in adults. UpToDate, Waltham, MA, 2020.

166. Prezioso D, Piccirillo G, Galasso R, Altieri V, Mirone V, Lotti T. Gynecomastia due to hormone therapy for advanced prostate cancer: a report of ten surgically treated cases and a review of treatment options. Tumori. 2004;90(4):410-415. 
167. Fradet Y, Egerdie B, Andersen M, et al. Tamoxifen as prophylaxis for prevention of gynaecomastia and breast pain associated with bicalutamide $150 \mathrm{mg}$ monotherapy in patients with prostate cancer: a randomised, placebo-controlled, dose-response study. Eur Urol. 2007;52(1):106-114. 


\section{Figures and Tables}

Fig. 1. Multidisciplinary approach to managing patients on androgen deprivation therapy (ADT).

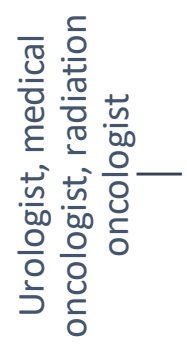

Patient started on ADT

\section{Baseline investigations}

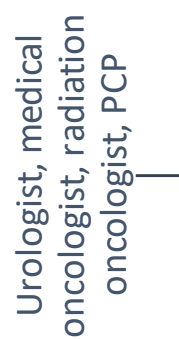

History: include previous MACE, risk factors for cardiac disease, previous VTE or stroke, falls risk

Physical_exam: include weight, waist circumference, BMI, height, blood pressure Laboratory studies: Obtain fasting plasma glucose level, oral glucose tolerance test or HgbA1c, lipid profile (total cholesterol, LDL, HDL), calcium level, 25-hydroxyvitamin D level

Other: Perform BMD testing using DXA scan; calculate 10-year major osteoporotic fracture risk using a validated tool

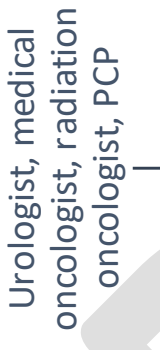

General recommendations and management of ADT-related complications as described in CUA guideline on ADT complications

Perform metabolic assessments at 6 to 12 month intervals for a minimum of 24 months ○— - Monitor blood pressure and treat hypertension for a target of $<130 / 80$

Monitor for dyslipidemia, insulin resistance and metabolic syndrome. Manage as per current best practice guidelines 


\section{Table 1. Summary of androgen deprivation therapy modalities}

1.1 Surgical orchiectomy

1.2 Medical castration

1.2.1 Gonadal androgen ablation

1.2.1.1 Leutenizing hormone releasing hormone (LHRH) agonists: leuprolide, goserelin, and triptorelin

1.2.1.2 LHRH antagonists: degarelix, relugolix

1.2.2 Androgen receptor antagonists (AA)

1.2.2.1 First generation: bicalutamide

1.2.2.2 Second generation: enzalutamide, apalutamide and darolutamide

1.2.3 Androgen synthesis inhibitors (CYP17 adrenal inhibitors): abiraterone acetate, ketoconazole

\begin{tabular}{|l|}
\hline Table 2. Benefits of exercise therapy in men receiving androgen deprivation therapy \\
\hline Physical domains \\
\hline Prevention of muscle loss and resultant decline in lean body mass \\
\hline Decreased body mass index \\
\hline Improved muscle strength \\
\hline Improvements in peak oxygen consumption and endothelial function \\
\hline Improved overall physical function \\
\hline Functional domains \\
\hline Lower levels of fatigue \\
\hline Decreased risk of falls and fractures \\
\hline Endocrine domains \\
\hline Improved insulin and glucose homeostasis \\
\hline Improved in lipid profile \\
\hline Multiple health-related quality of life domains \\
\hline
\end{tabular}




\begin{tabular}{|c|c|c|}
\hline Name of agent & Mechanism of action & Doses (select one option) \\
\hline Alendronate (Fosamax) & Bisphosphonate & $\begin{array}{l}-10 \mathrm{mg} \text { orally daily } \\
-70 \mathrm{mg} \text { orally weekly }\end{array}$ \\
\hline Risedronate (Actonel) & Bisphosphonate & $\begin{array}{l}-5 \mathrm{mg} \text { orally daily } \\
-35 \mathrm{mg} \text { orally weekly } \\
-150 \mathrm{mg} \text { orally monthly }\end{array}$ \\
\hline Zoledronic acid (Aclasta) & Bisphosphonate & $\begin{array}{l}-5 \mathrm{mg} \text { intravenously } \\
\text { annually }\end{array}$ \\
\hline Denosumab (Prolia) & RANK ligand inhibitor & $\begin{array}{l}-60 \text { mg subcutaneously } \\
\text { every } 6 \text { months }\end{array}$ \\
\hline
\end{tabular}

\begin{tabular}{|c|c|c|c|}
\hline Name of agent & Dose & $\begin{array}{l}\text { Mechanism of } \\
\text { action }\end{array}$ & $\begin{array}{l}\text { Health Canada- } \\
\text { approved for hot } \\
\text { flashes }\end{array}$ \\
\hline $\begin{array}{l}\text { Medroxyprogesterone } \\
\text { acetate (Provera) }\end{array}$ & $\begin{array}{c}20 \mathrm{mg} \text { orally } \\
\text { daily }\end{array}$ & $\begin{array}{c}\text { Synthetic } \\
\text { derivative of } \\
\text { progesterone }\end{array}$ & No \\
\hline $\begin{array}{l}\text { Megestrol acetate } \\
\text { (Megace) }\end{array}$ & $\begin{array}{l}20 \mathrm{mg} \text { orally } \\
\text { twice daily }\end{array}$ & $\begin{array}{c}\text { Synthetic } \\
\text { derivative of } \\
\text { progesterone }\end{array}$ & No \\
\hline $\begin{array}{l}\text { Cyproterone acetate } \\
\text { (Androcur) }\end{array}$ & $\begin{array}{l}100 \mathrm{mg} \text { orally } \\
\text { daily }\end{array}$ & Antiandrogen & $\begin{array}{c}\text { No (approved for } \\
\text { palliative treatment of } \\
\text { patients with advanced } \\
\text { prostate } \\
\text { adenocarcinoma) }\end{array}$ \\
\hline Gabapentin (Neurontin) & $\begin{array}{l}900 \mathrm{mg} \text { orally } \\
\text { daily }\end{array}$ & $\begin{array}{c}\text { Antiepileptic } \\
\text { agent }\end{array}$ & No \\
\hline Venlafaxine (Effexor) & $\begin{array}{c}75 \mathrm{mg} \text { orally } \\
\text { daily }\end{array}$ & $\begin{array}{c}\text { Selective } \\
\text { serotonin reuptake } \\
\text { inhibitor }\end{array}$ & No \\
\hline
\end{tabular}


Table 5. Summary of adverse events associated with androgen deprivation therapy

\begin{tabular}{|c|c|c|}
\hline Complication & Summary of events & Management \\
\hline Cardiovascular disease & $\begin{array}{l}\text { Increased risk of cardiac events } \\
\text { Increased risk of stroke } \\
\text { Increased risk of DVT/PE }\end{array}$ & $\begin{array}{l}\text { 1. Lifestyle changes to promote healthy diet and weight } \\
\text { 2. Smoking cessation } \\
\text { 3. Exercise therapy } \\
\text { 4. Monitoring and medical optimization of blood glucose, blood pressure, lipid profiles } \\
\text { 5. Consider use of GnRH antagonist in patients with significant cardiac comorbidities } \\
\text { 6. Consider referral to cardiac oncology }\end{array}$ \\
\hline Change in body composition & $\begin{array}{l}\text { Increased BMI } \\
\text { Increased percentage body fat } \\
\text { Decreased muscle mass }\end{array}$ & $\begin{array}{l}\text { 1. Lifestyle changes to promote healthy diet and weight } \\
\text { 2. Exercise therapy } \\
\text { 3. Monitoring and medical optimization of blood glucose, blood pressure, lipid profiles }\end{array}$ \\
\hline Change in metabolic parameters & $\begin{array}{l}\text { Insulin resistance/glucose intolerance } \\
\text { Increased risk for incident diabetes } \\
\text { Worse glycemic control } \\
\text { Altered lipid profiles } \\
\text { Increased risk for metabolic syndrome }\end{array}$ & $\begin{array}{l}\text { 1. Lifestyle changes to promote healthy diet and weight } \\
\text { 2. Exercise therapy } \\
\text { 3. Monitoring and medical optimization of blood glucose, blood pressure, lipid profiles }\end{array}$ \\
\hline Bone health & $\begin{array}{l}\text { Decreased BMD } \\
\text { Increase risk for osteoporosis } \\
\text { Incrased risk for clinical fractures }\end{array}$ & $\begin{array}{l}\text { 1. Smoking and alcohol cessation (all men) } \\
\text { 2. Adequate calcium intake ( } 1200 \mathrm{mg} \text { daily) and vitamin D supplementation ( } 800-1000 \text { IU daily) (all men) } \\
\text { 3. Exercise therapy (all men) } \\
\text { 4. Pharmacological therapy with a bisphosphonate or denosumab for men with risk factors for bone fracture (ie. previous history of low } \\
\text { trauma fracture, diagnosis of osteoporosis, moderate or high } 10 \text {-year fracture risk) }\end{array}$ \\
\hline Hot flashes & Hot flashes & $\begin{array}{l}\text { 1. Avoidance of triggers } \\
\text { 2. Pharmacological therapy } \\
\text { 3. Consider acupuncture }\end{array}$ \\
\hline Breast events & $\begin{array}{l}\text { Gynecomastia } \\
\text { Mastodynia }\end{array}$ & $\begin{array}{l}\text { 1. Treatment with tamoxifen or low dose RT (tamoxifen preferred) } \\
\text { 2. Surgical management for select patients }\end{array}$ \\
\hline Cognitive function & $\begin{array}{l}\text { Concentration } \\
\text { Memory } \\
\text { Dementia }\end{array}$ & $\begin{array}{l}\text { 1. Evidence for causality is weak } \\
\text { 2. Appropriate patient education and monitoring of symptoms }\end{array}$ \\
\hline Fatigue and anemia & & $\begin{array}{l}\text { 1. Exercise therapy for fatigue } \\
\text { 2. Work up secondary causes of anemia and referral to hematology }\end{array}$ \\
\hline Impaired sexual function & $\begin{array}{l}\text { Decreased penile and testicular size } \\
\text { Loss of libido } \\
\text { Decreased sensitivity to sexual stimulation } \\
\text { Erectile dysfuncton }\end{array}$ & $\begin{array}{l}\text { 1. Appropriate pre-treatment counselling } \\
\text { 2. Sex therapy } \\
\text { 3. PDE-5 inhibitor therapy where appropriate } \\
\text { 4. Intermittent ADT }\end{array}$ \\
\hline Quality of life & Multiple domains & $\begin{array}{l}\text { 1. Exercise therapy } \\
\text { 2. Intermittent ADT where appropriate }\end{array}$ \\
\hline
\end{tabular}

